\title{
Typhoon Rainfall over Taiwan Area: The Empirical Orthogonal Function Modes and Their Applications on the Rainfall Forecasting
}

\author{
Tien-Chiang $\mathrm{Yeh}^{1, *}$
}

(Manuscript received 16 July 2001, in final form 3 October 2002)

\begin{abstract}
Distribution of 6-h accumulated typhoon rainfall over Taiwan area is investigated through empirical orthogonal function (EOF) analysis. The data set used includes the rainfall of 20 Central Weather Bureau surface stations when typhoons were inside the domain between $18^{\circ} \mathrm{N}$ and $28^{\circ} \mathrm{N}$, $116^{\circ} \mathrm{E}$ and $126^{\circ} \mathrm{E}$, from 1961 to 1996 . Analysis results show that the first three EOF modes are well separated from the other modes. Those three modes contain about $66 \%$ of the total rainfall variances. At some stations, only those three modes can effectively represent the station rainfall. The first EOF mode not only reveals the in-phase increasing or decreasing rainfall at all stations of Taiwan but also shows that larger rainfall occurs at stations with higher elevation and larger slope. The enhancement of rainfall in mountainous areas is an indication of topography effect on redistributing rainfall. The second mode and the third mode both show out-of-phase distribution of rainfall over Taiwan when typhoons are nearby. The rainfalls are enhanced on the up-wind sides of the mountain, and the rainfalls are suppressed on the down-wind sides. Those distributions again reveal the effects of redistributing rainfall by Central Mountain Range of Taiwan.

To demonstrate how the EOF modes may be used on typhoon rainfall forecasting, several forecasting methods are evaluated. Those methods include four basic methods and four ensemble forecasts. The basic methods are: Climatology Average Method, Deviation Persistence Method, regression equation forecast based on station rainfall, and regression equation forecast based on the amplitude of the first three EOF modes. The ensemble forecasts are the simple averages taken from the last three basic methods. The results show those basic methods are compatible with each other, except the Climatology Average Method that underestimates all heavier rains and is outperformed by the others. Since the amplitudes of EOF modes depend on how the rainfall is distributed spatially over all stations of Taiwan, a forecast method based on EOF modes is capable of providing different
\end{abstract}

\footnotetext{
${ }^{1}$ Central Weather Bureau, Taipei, Taiwan ROC

* Corresponding author address. Dr. Tien-Chiang Yeh, Central Weather Bureau, 64 Kung-Yuan Rd. Taipei, Taiwan, 100 ROC; E-Mail: yeh@cwb.gov.tw
} 


\title{
information from other methods that based on factors only related to a single station. The study also shows that the ensemble forecasts outperform their corresponding member forecasts.
}

\author{
(Key words: Typhoon rainfall, Empirical orthogonal function analysis, \\ Regression, Typhoon rainfall forecast)
}

\section{INTRODUCTION}

The island of Taiwan is situated in one of the main paths of north Western Pacific typhoons. On average, four typhoons affect the island each year. As Central Mountain Range covers the small-scale isolated island with peaks higher than 3,900 meters, therefore many interesting weather-topography interaction phenomena have been observed and documented. In particular, the effect of the mountains on the motion and structure of typhoons have been attentively studied (Brand and Blelloch 1974; Wang 1980; Chang 1982; Bender et al. 1987; Chang et al. 1993; Yeh and Elsberry 1993; and others).

In addition to the academic studies, the forecasting of the destructive typhoons also is one of the most important operational tasks of the local weather services. Shieh (1986) reported that the majority of economic losses due to weather related events in Taiwan have been caused by the strong winds, heavy rains and sometimes storm surges associated with typhoons. For example, near $2,000 \mathrm{~mm}$ rains were observed in a 48-hour period on the central mountain area during the invasion of typhoon Herb in 1996. The heavy rains induced severe flooding and massive debris flow. Heavy rains again caused serious economic and life losses over northern Taiwan associated with typhoon Zeb in 1997 and typhoon Winnie in 1998. Understanding and achieving better forecasts of typhoon rainfall over Taiwan have become one of the highest priority tasks of the local weather services and the meteorology community.

As to the typhoon forecasts, many studies have focused on the tropical cyclone motion forecast (e.g. Elsberry 1995) and intensity forecast (e.g. Jarvinen and Neumann 1979; DeMaria and Kaplan 1994). Many skillful objective aids have been developed for operational usage. On the other hand, as reviewed by Chen (1995), typhoon rainfall was less studied. More complete methods for operational forecast of typhoon rainfall remain to be developed. For example, the National Hurricane Center/Tropical Prediction Center of United States issued track and intensity forecasts if a hurricane formed. However no rainfall forecasts were included. Over the continental United States, the hurricane rainfall forecasts were included in their daily rainfall forecast. The effects of hurricanes on precipitation were considered in a relatively simple way (Opitz et al. 1995). Recently, the potentials of using numerical model rainfall forecasts were examined (e.g. Li et al. 1997; Kuo and Wang 1997). However, more verification is required to show numerical models are effective for typhoon rainfall forecasting.

In Taiwan, Wu and Chi (1973) have shown that typhoon rainfall over Taiwan area is correlated with the locations of the typhoon center. A technique using the climatology average (based on the spatial distribution of typhoon center) to forecast typhoon rainfall was then developed (Wang et al. 1986) and was adopted (Wu and Shieh 1990) to be one of the opera- 


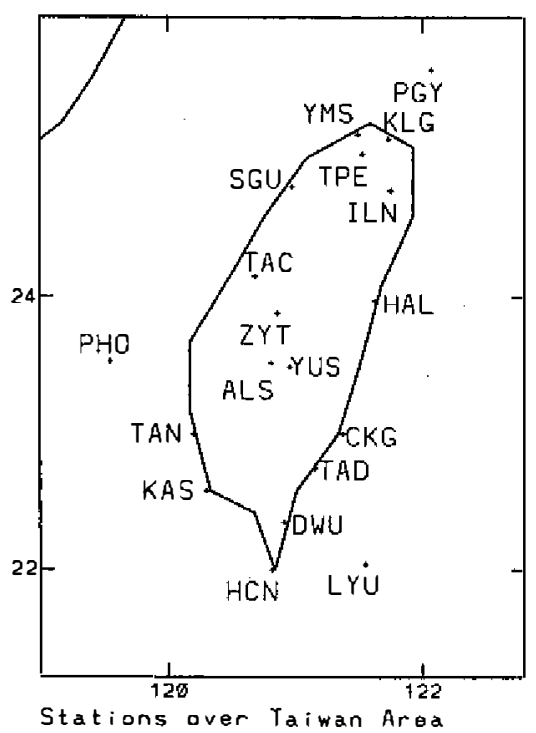

Fig. 1. The geophysical location of Taiwan and the distribution of the surface stations.

Table 1. List of surface stations. The stations are in alphabetic order of the identifier code. Rainfalls at YMS are the averages of rainfalls at station 46691 and at station 46693.

\begin{tabular}{|cclccr|}
\hline $\begin{array}{c}\text { Identifier } \\
\text { Code }\end{array}$ & $\begin{array}{c}\text { Station } \\
\text { Number }\end{array}$ & $\begin{array}{c}\text { Station } \\
\text { Name }\end{array}$ & $\begin{array}{c}\text { Latitude } \\
(\mathrm{N})\end{array}$ & $\begin{array}{c}\text { Longitude } \\
\left({ }^{\circ} \mathrm{E}\right)\end{array}$ & $\begin{array}{r}\text { Height } \\
(\mathrm{m})\end{array}$ \\
\hline ALS & 46753 & A-Li-Shan & 23.52 & 120.80 & 2,413 \\
CKG & 46761 & Chen-Kung & 23.00 & 121.36 & 33 \\
DWU & 46754 & Ta-Wu & 22.35 & 120.90 & 8 \\
ILN & 46708 & I-Lan & 24.77 & 121.75 & 7 \\
LYU & 46762 & Lan-Yu & 22.04 & 121.55 & 324 \\
KAS & 46744 & Kao-Hsiung & 22.58 & 120.30 & 2 \\
KLG & 46694 & Kee-Lung & 25.14 & 121.73 & 27 \\
HAL & 46699 & Hua-Lien & 23.97 & 121.62 & 16 \\
HCN & 46759 & Heng-Chun & 22.00 & 120.75 & 22 \\
PGY & 46695 & Peng-Chia-Yu & 25.63 & 122.07 & 99 \\
PHO & 46735 & Peng-Hu & 23.53 & 119.55 & 11 \\
SGU & 46757 & Hsin-Chu & 24.80 & 120.97 & 34 \\
TAC & 46749 & Tai-Chung & 24.15 & 120.68 & 84 \\
TAD & 46766 & Tai-Tung & 22.75 & 121.15 & 9 \\
TAN & 46741 & Tai-Nan & 23.00 & 120.20 & 13 \\
TPE & 46692 & Taipei & 25.01 & 121.52 & 6 \\
YMS & 46691 & Am-Pu & 25.19 & 121.52 & 837 \\
YUS & 46693 & Chu-Tze-Hu & 25.17 & 121.53 & 603 \\
ZYT & 46755 & Yu-Shan & 23.49 & 120.95 & 3,845 \\
& 46765 & Jih-Yuen-Tan & 23.88 & 120.85 & 1,015 \\
\hline
\end{tabular}


tional typhoon rainfall forecast aids by the Central Weather Bureau, Taiwan. Yeh et al. (1999) and Yeh et al. (2000) lately have indicated that the forecasts based on climatology average is capable of showing the trend of typhoon rainfall. However, the method underestimates all of the heavier rains. By considering the deviations from the climatology average, they examined the so-called "Deviation Persistence Method" and found that the forecasts were improved by simply assuming the deviations from the climatology average persist within 24 hours.

In addition, to show that the station rainfall has a relationship with the typhoon center location, Yeh et al. (2000) also indicated that there were relationships among typhoon rainfall levels at nearby stations. For example, their figure 1 showed that the rainfall over northwestern Taiwan increases gradually from northern stations to southern stations when typhoons pass through northern Taiwan westward. When northward moving typhoons pass by east/west coast of Taiwan, the rainfall over eastern/western Taiwan will increase gradually from southern stations to northern stations. Those results could be a useful guide in rainfall forecasting if quantitative relationships can be obtained.

This study aims to show the spatial distribution of typhoon rainfall over Taiwan. Demonstrations using that information on rainfall forecasting are also given. The rainfall we focused on is the 6-hour accumulated rainfall, since skillful 6-hour leading forecasts of typhoon rainfall are essential to the water resource management and disaster mitigation in Taiwan. Section 2 states the empirical orthogonal function analysis we applied and the data we examined. Discussions of each rainfall mode of the empirical orthogonal function analysis are in Section 3. Evaluations of the rainfall forecast based on the empirical orthogonal function analysis modes are in Section 4. Finally, the summary is given in Section 5.

\section{DATA AND THE EMPIRICAL ORTHOGONAL FUCTION ANALYSIS}

The empirical orthogonal function (EOF) analysis has become a common approach in meteorology data analysis. The approach is that a data field is represented as the sum of the product of time varying amplitudes and associated spatial orthogonal functions. Those amplitudes and functions, or in other words, modes, are chosen to be the most efficiently approximate the field in the way that the mean-square error between the original and the represented fields is minimum (Barnett 1977). Therefore, the EOF analysis often enables a description of the variations of a complex meteorology field with a relatively small number of functions and associated amplitudes. Furthermore, usually, these derived empirical functions are amenable to physical interpretation of the meteorology phenomena recorded in the data.

To identify the spatial structure of typhoon rainfall patterns over Taiwan, the EOF analysis was applied. The analysis procedure we carried out is the same as that of Chang et al. (1993). The observation data over Taiwan from Central Weather Bureau (CWB) were analyzed directly on non-uniform-distibuted surface stations without applying any objective analyses to transform datum into regular grids. The area of study and the location of surface stations are shown in Fig. 1. In the figure the stations are coded in three-digit identifiers and are explained in Table 1. The period of rainfall data is from 1961 to 1996. Note that several station datum CWB had collected were not included in the analysis because those stations had not started operation during the earlier years of 1960s. Another consideration is that station 46691 
and station 46693 are located very close to each other. Instead of including two individual rainfall observations in the EOF analysis, only their means were used and treated as a station.

A case was selected in the study when at any time a typhoon center was located inside the domain of $18^{\circ} \mathrm{N}-28^{\circ} \mathrm{N}, 116^{\circ} \mathrm{E}-126^{\circ} \mathrm{E}$ and there were no other typhoon centers inside the domain simultaneously. The hourly center locations were linear interpolated from the best tracks of Joint Typhoon Warning Center at Hawaii, United States. As a result, there were 14,747 hourly cases selected from 324 typhoons from 1961 to 1996 . Figure 2 shows the occurrence of cases per $2^{\circ} \times 2^{\circ}$. Inside most of the selected domain, the case numbers are greater than 400 . Areas with more cases are near $19^{\circ} \mathrm{N}$. Near Taiwan, areas with relatively more cases are over northern Taiwan and areas with relatively few cases are over southwestern Taiwan. The areas of relatively few cases also extend from southwestern Taiwan to the nearby Taiwan Strait. A similar case distribution was shown by Chang et al. (1993), while their cases were selected from a slightly smaller domain of $19^{\circ} \mathrm{N}-27^{\circ} \mathrm{N}, 117^{\circ} \mathrm{E}-125^{\circ} \mathrm{E}$ and for a shorter period of from 1971 to 1990.

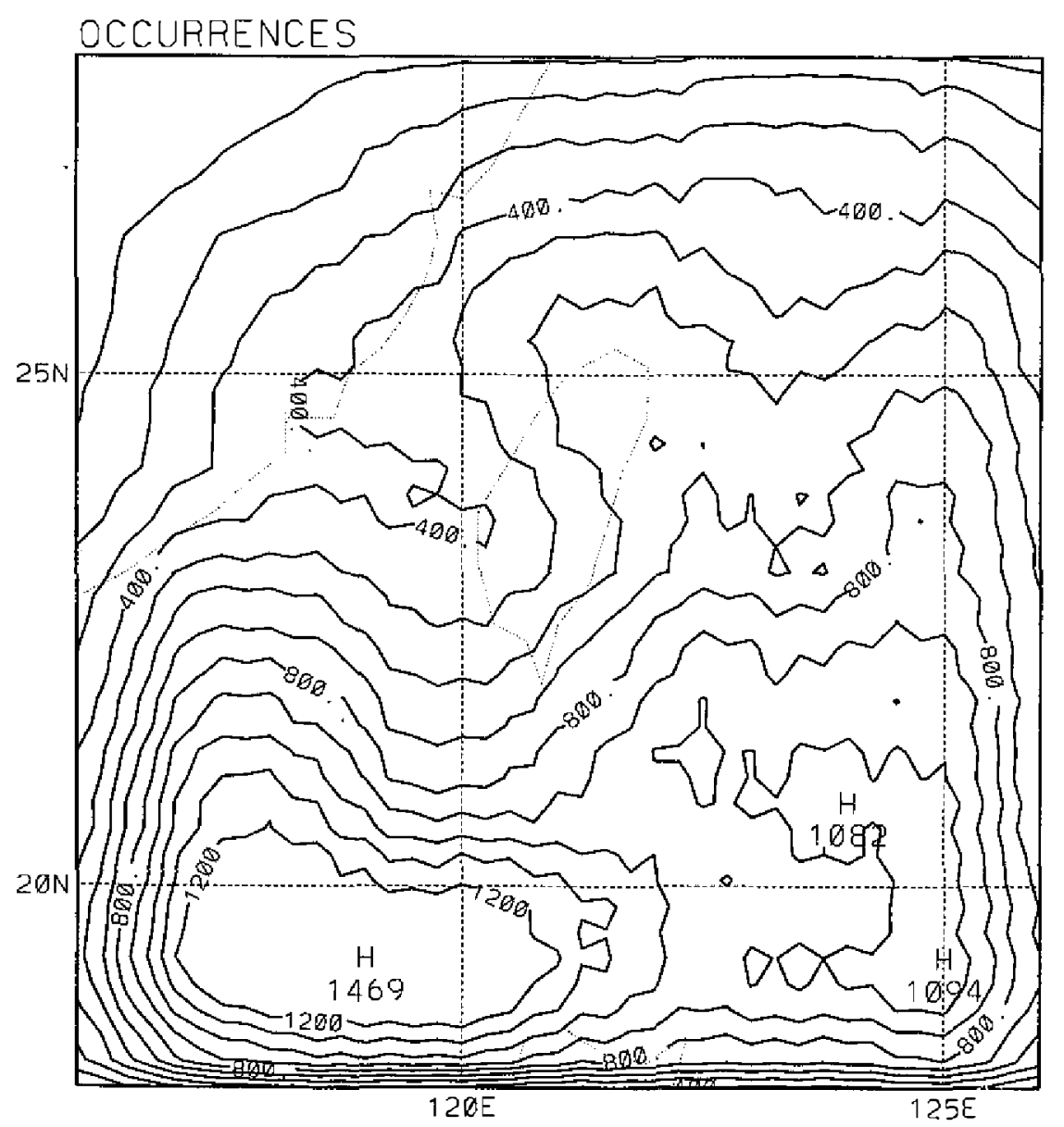

Fig. 2. Occurrences of the typhoon centers at each of $2^{\circ} \times 2^{\circ}$ grid points. 


\section{RAINFALL EOF MODES}

The mean 6-hour accumulated rainfalls of the 14,747 cases are shown in Fig. 3. The 6hour accumulated rainfall is defined as the total rainfall within 6 hours before a given time. Areas of smaller mean rainfall are over western Taiwan and areas of larger mean rainfall are over southeastern and central Taiwan. The range is from 3 to $13 \mathrm{~mm}$. The mean rainfalls are relatively small compared to our expectation of typhoon rainfall. Figure 4 displays the mean station rainfall when typhoons were inside each smaller $2^{\circ} \times 2^{\circ}$ sub-domain. The smaller mean rainfall in Fig. 3 is owing to many cases with typhoon centers still a few degrees away from Taiwan. Very small rainfalls were observed when centers were located in the outer ring of the domain. Rainfalls increased gradually when typhoor centers moved closer to Taiwan. When typhoon centers were inside $20^{\circ} \mathrm{N}-26^{\circ} \mathrm{N}, 118^{\circ} \mathrm{E}-124^{\circ} \mathrm{E}$ larger than $20 \mathrm{~mm}$ rains were found at some stations of Taiwan. Even heavier rains fell when typhoon centers were inside $22^{\circ} \mathrm{N}$ $26^{\circ} \mathrm{N}, 120^{\circ} \mathrm{E}-124^{\circ} \mathrm{E}$. In three of the four sub-domains, the mean total rainfalls of these 19 stations were greater than $400 \mathrm{~mm}$.

Another feature shown in Fig. 4 is that the mean rainfall at a station is related to the location of typhoon center. Larger rainfalls occur when centers move right over the station or when the stations are in a situation of typhoon lower level cyclonical circulation flowing against the mountain slope. For example, over southeastern Taiwan, the largest rainfall occurred when centers were right over southern Taiwan. For centers located inside other sub-domains, larger rainfalls occurred when centers were south of $22^{\circ} \mathrm{N}$, for which the westward cyclonical flow was expected over southeastern Taiwan. The rains could be enhanced due to flow against the mountain. Similar topography enhanced rainfall fell over westem Taiwan when typhoon centers were at north of $24^{\circ} \mathrm{N}$ and east of $120^{\circ} \mathrm{E}$. Areas of the most distinct rainfall were at ALS and at YMS. Both stations are located at higher elevation and greater slope. Much heavier rainfalls were observed than that of their neighbor stations.

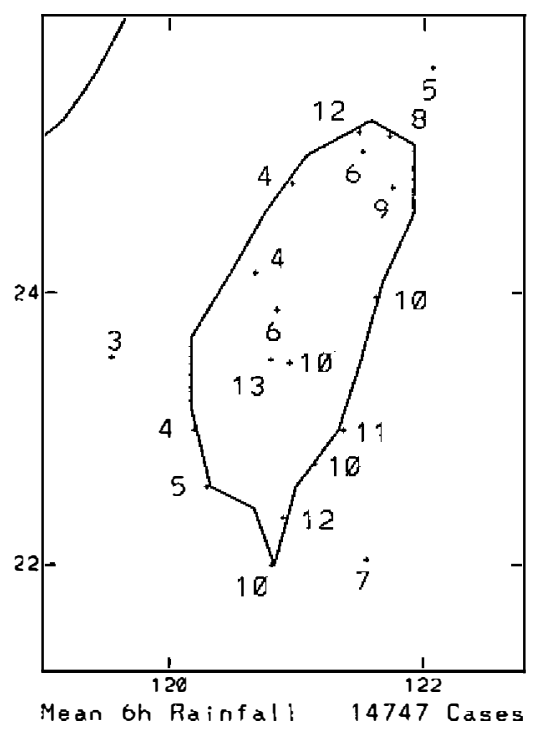

Fig. 3. Mean 6-hour accumulated rainfall (mm) of the 14,347 cases at each station. 
The rainfall EOF modes calculated after the station means, shown in Fig. 3, had been subtracted from the observed rainfall. The percentage variances of the first $10 \mathrm{EOF}$ modes are $34.5 \%, 18.6 \%, 13 \%, 5.3 \%, 4.0 \%, 3.3 \%, 2.7 \%, 2.6 \%, 2.5 \%$ and $2.3 \%$, respectively. It is obvious that the percentage variances of the first three modes are relatively large and are separated from the remainder modes. Therefore, only the first three modes (hereafter mode-1, mode-2, and mode-3), which accumulate about $66 \%$ of the total rainfall variances, were further examined. By comparing with the percentage variances of the surface pressure EOF modes presented by

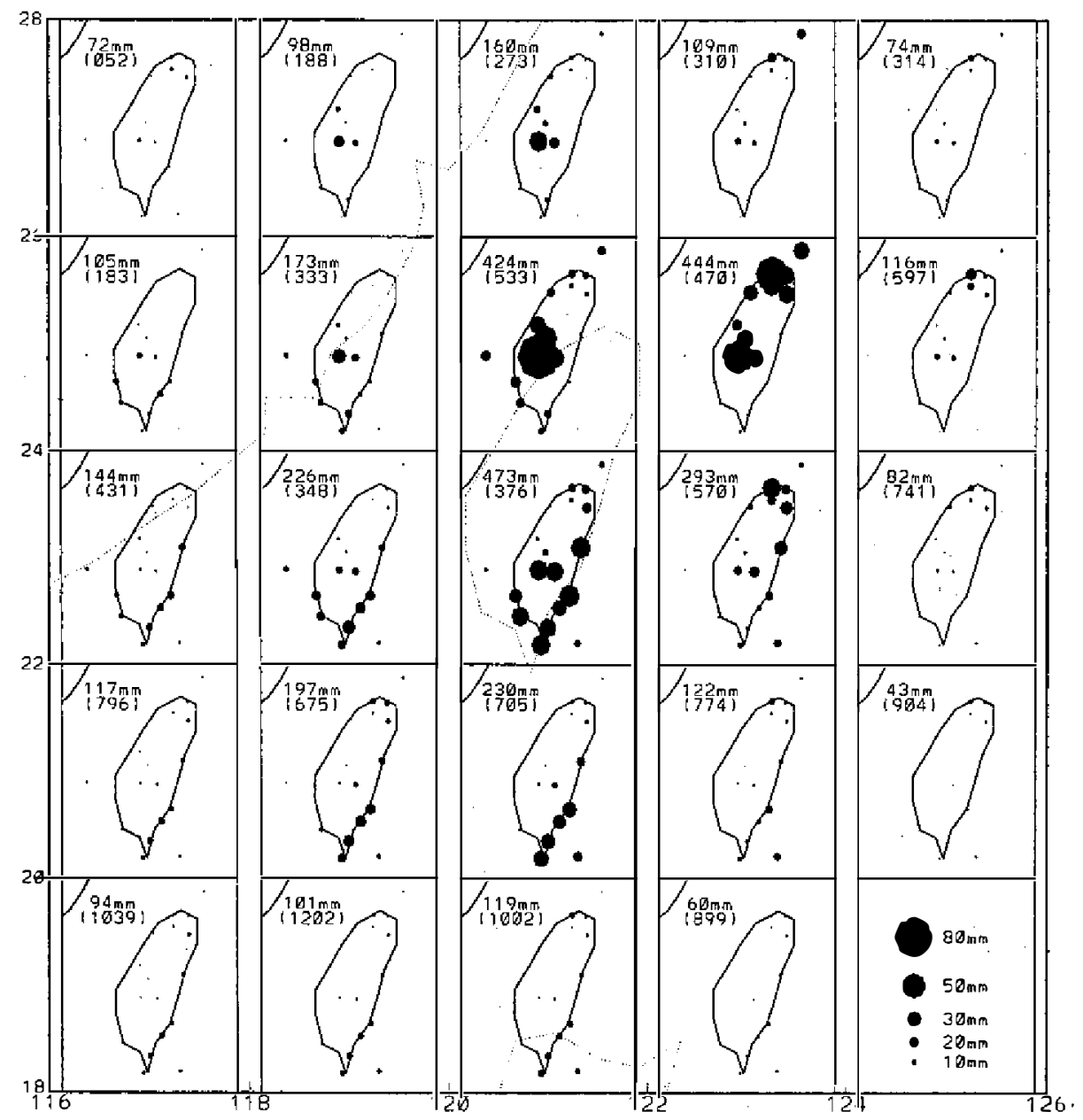

Fig. 4. Mean 6-hour accumulated rainfalls (scales in lower right panel) as a function of typhoon center location. Each of the 24 panels covers a $2^{\circ} \times 2^{\circ}$ grid square and shows the 6-h accumulated rainfall at 19 stations and the 19station total rainfall over Taiwan (value at each upper left corner) for those cases (cases numbers inside the parentheses) when typhoon centers are located inside the particular grid square. 
Chang et al. (1993), we found mode- 1 is no longer an overwhelming dominant mode in typhoon rainfall. Higher order modes of typhoon rainfall contain larger percentage variances. In other words, typhoon rainfall over Taiwan is more complicated and is smaller scaled than that of the surface pressure.

Figure 5 plots the first three EOF functions (hereafter Mode-1, Mode-2, and Mode-3). The values in Fig. 5 are the rainfall at each station when the amplitude of each mode equals one standard deviation. In other words, in case of a rainfall event with normalized amplitudes of mode- 1 , mode- 2 and mode- 3 respectively equal a1, a2, and a3, the total rainfall contributed from the first three modes will be the sum of a1 times Mode-1, a2 times Mode-2, and a3 times Mode-3. Here, the normalization was defined as dividing by their standard deviations. In Fig. $4 \mathrm{a}$, the values are all in same sign. Mode-1 increases or decreases the rainfall simultaneously over the whole of Taiwan.

The amplitude of mode-1 depends primarily on the location of typhoon center. Figure 6a is a plot of the center-mean amplitudes of mode- 1 . The center-mean amplitudes were made by averaging the amplitude of all cases with centers located inside a circle of radius equals $2^{\circ}$. The figure depicts how the mean amplitudes vary with center locations. The amplitudes of mode-1 are getting larger when the centers are moving close to Taiwan. This mode reflects the in-phase increasing/decreasing rainfalls over the entire island when typhoons move close-to/ away-from Taiwan.

Although all the signs are the same, rainfall at 19 stations of Mode- 1 have differences in magnitudes. The heaviest rains fall on the mountainous area of central Taiwan with $35 \mathrm{~mm}, 19$ $\mathrm{mm}$, and $16 \mathrm{~mm}$ at ALS, YUS, and ZYT, respectively. Areas of heavier rains extend farther to the north. Rainfall of $10 \mathrm{~mm}$ is found at TAC. Another region of larger rains is to north tip of
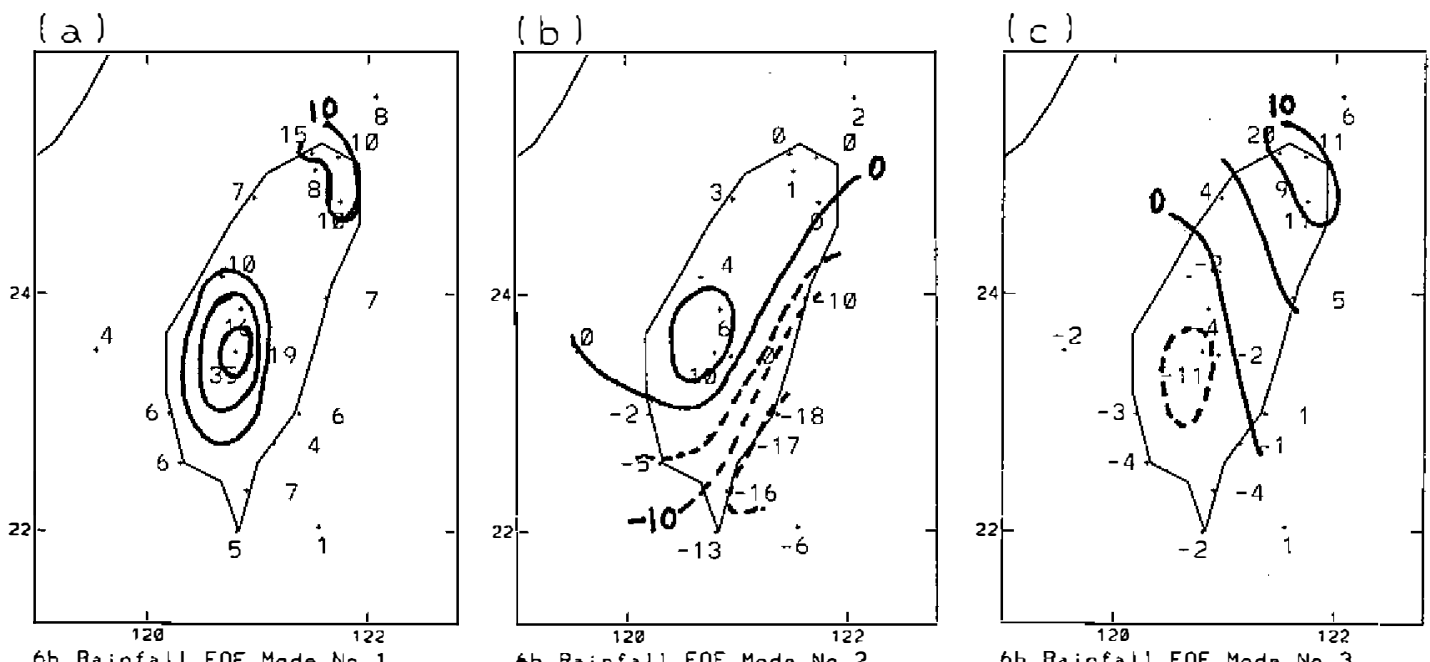

Fig. 5. The rainfall pattern of the empirical orthogonal function (a) mode 1, (b) mode 2, and (c) mode 3 at one standard deviation. Contour intervals are $5 \mathrm{~mm}$. 

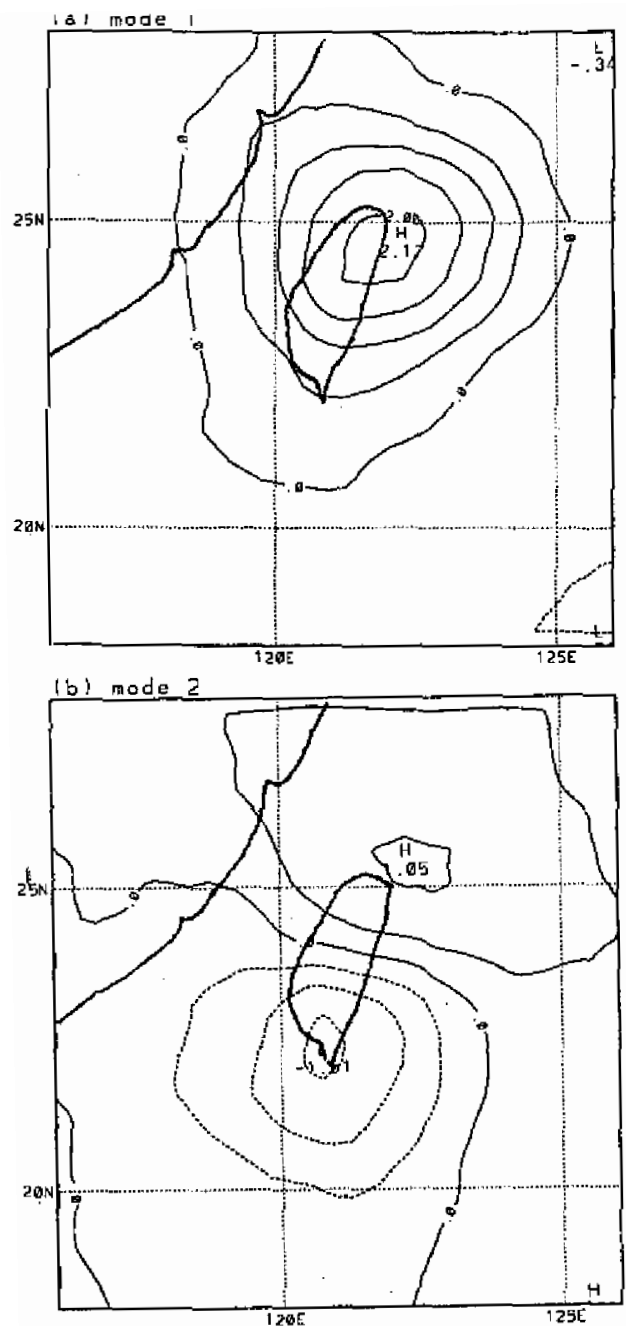

Fig. 6. The distribution of the normalized amplitude (intervals of 0 . 25) according to the typhoon center location for empirical orthogonal function (a) mode 1, (b) mode 2 , and (c) mode 3 .

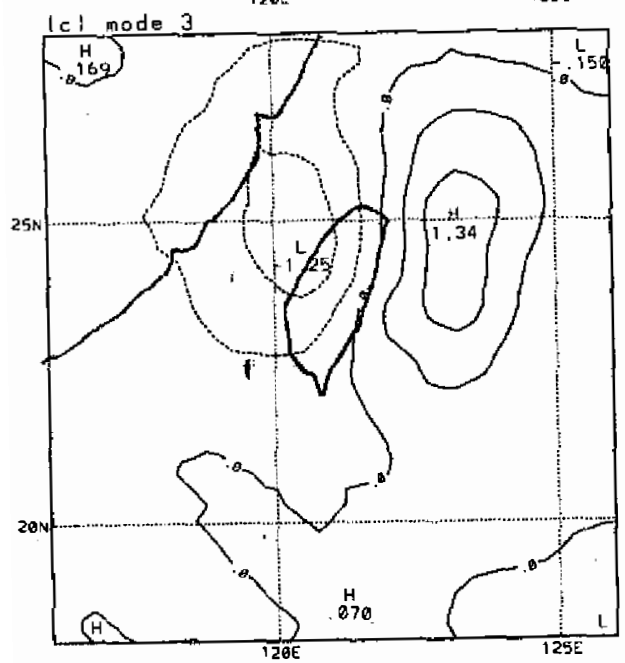


Taiwan, in which $15 \mathrm{~mm}$ rainfall is found at YMS and about 8 to $10 \mathrm{~mm}$ rainfall is found at TPE, KLG, and ILA. The center-mean amplitude diagram, Fig. 6a, shows that mode- 1 has the largest area-mean amplitude when centers are near the northeastern coast. The normalized amplitude is about 2.2. The areas with amplitudes greater than 1.5 are over northern Taiwan and the nearby ocean east of Taiwan. This is consistent with Fig. 4. The figure shows the rainfalls on central and northern Taiwan are larger than other areas when typhoon centers are located inside the $2^{\circ} \times 2^{\circ}$ sub-domains of $24^{\circ} \mathrm{N}-26^{\circ} \mathrm{N}, 120^{\circ} \mathrm{E}-122^{\circ} \mathrm{E}$ and $24^{\circ} \mathrm{N}-26^{\circ} \mathrm{N}, 122^{\circ} \mathrm{E}-$ $124^{\circ} \mathrm{E}$. As mentioned, the enhancement of rainfall on central and northern Taiwan is likely caused by topography effect. Therefore, in addition to showing the in-phase trend of increasing or decreasing of rainfall on entire Taiwan, Mode- 1 also includes part of the result of topography effect on re-distributing typhoon rainfall.

EOF Mode-2 (Fig. 5b) has a rainfall distribution very different from Mode-1. Mode-1 has an in-phase rainfall distribution over all of Taiwan, but Mode- 2 has an out-of-phase rainfall distribution between northwestern Taiwan and southeastern Taiwan. Positive values are over northwestern Taiwan with a maximum value of $10 \mathrm{~mm}$ at ALS. Negative values are over southeastern Taiwan with a minimum value of $-18 \mathrm{~mm}$ at TAD. The 'node line' (contour of 0 $\mathrm{mm}$ ) is from PHO to YUS and then extends northeastward to ILA in a way somewhat parallel to the mountain range. The amplitudes of mode- 2 also depend primarily on the location of typhoon center. Figure $6 \mathrm{~b}$ shows dipole shaped contour lines. The center-mean amplitude of mode- 2 has positive/negative values when typhoon centers are located at north/south of roughly $24^{\circ} \mathrm{N}$. When typhoons are located at the areas of positive amplitudes, the rainfall over northwestern/southeaster Taiwan will have positive/negative values. When typhoons are located at locations of negative amplitude, the rainfall over northwestern/southeaster Taiwan will have negative/positive values. Since eastward/westward components of the lower level typhoon cyclonical flow are expected when typhoon centers are located at the positive/negative area of Fig. Sb, the increasing/decreasing of rainfall on windward/leeward side of maintain is consistent with the topography effect of enhancing/depressing rainfall on upslope/down-slope of mountains. Mode- 2 reveals clearly the topography effect of re-distributing typhoon rainfall due to the north-to-south oriented longer-axis of Central Mountain Range.

The contributions of mode- 2 on station rainfall are confirmed in the mean rainfall diagram (Fig. 4). For example, the areas of larger rainfall are very different for cases of typhoon located in southern part of domain from those of cases located in northern part of domain. More rainfalls occur in southeastern Taiwan when centers are located in the south and more rainfalls occur on northwestern Taiwan when centers locate in the north. The latitude separating these two kinds of distributions is roughly at $24^{\circ} \mathrm{N}$, a similar location to the zero contours in Fig. 6b. Another example is that significant amounts of rainfall occur in southeast coastal areas when typhoon centers are in South China Sea, Luzon Island, or the Bashi Channel. All of these cases are typhoons still far away from Taiwan.

Mode-3 (Fig. 5c) has a similar out-of-phase rainfall distribution to that of Mode-2, but the contour lines are oriented in different directions. As the 'node line' of Mode- 2 orients along the longer-axis of Central Mountain Range on northeastern Taiwan, the 'node line' of Mode3 orients from northwest to southeast and passes across the Central Mountain Range dividing Taiwan into northern and southern halves with roughly equal areas. The maximum rainfall of 
Mode- 3 is $20 \mathrm{~mm}$ at YMS. Areas with larger than $10 \mathrm{~mm}$ rainfall are over the northern tip of Taiwan. The amplitudes of mode- 3 also depend primarily on the typhoon center location. Figure $5 \mathrm{c}$ shows the positive phase of rains will occur when typhoon centers move close to the east coast of Taiwan. The normalized amplitudes are larger than ones when centers are located inside the domain of $22^{\circ} \mathrm{N}-26^{\circ} \mathrm{N}, 123^{\circ} \mathrm{E}-124^{\circ} \mathrm{E}$. Larger than $10 \mathrm{~mm}$ 6-hour accumulated rainfall will be contributed from mode- 3 on northern tip of Taiwan when the centers move into this domain. The enhancements of rainfall in northern Taiwan and the suppressions of rainfall in southern Taiwan are consistent with the topography effect of redistribution rains on up-slope and down-slope of mountains as the northerly components of the typhoon cyclonic flow are expected over the Taiwan area.

On the negative phase of mode-3, the maximum rainfall is $11 \mathrm{~mm}$ at ALS. Areas with heavier rains extend from the Central Mountain area southward to the coastal area. Figure $6 c$ shows the negative phase of rain will occur when typhoon centers move right over or to the west of Taiwan. Specially, larger rainfall will occur in southern Taiwan when centers move to western Taiwan and the central Taiwan Straits where the normalized amplitudes are less than -1 . As mentioned, the result of topography effect is consistent with the enhancing or suppressing of rainfall in negative phase of Mode-3. Over southem/northem Taiwan, southerly components of typhoon cyclonic flow are up-slope/down-slope the mountains when typhoon centers are located west of Taiwan. Mode-3 reveals clearly the effect of redistribution of typhoon rainfall by the west-to-east oriented shorter-axis of the Central Mountain Range.

The contributions of mode- 3 on total rainfall are also confirmed in Fig. 4. For example, large rainfalls occur in northern Taiwan when typhoon centers are located inside the subdomain of $22^{\circ} \mathrm{N}-26^{\circ} \mathrm{N}, 122^{\circ} \mathrm{E}-124^{\circ} \mathrm{E}$. This kind of distribution is not explained by mode- 1 , as the rainfalls are smaller when the centers move westward closer to Taiwan. Part of the rainfall distribution is contributed by mode- 2 when centers locate inside sub-domain of $24^{\circ} \mathrm{N}-26^{\circ} \mathrm{N}$, $122^{\circ} \mathrm{E}-124^{\circ} \mathrm{E}$. When centers are located inside the sub-domain of $22^{\circ} \mathrm{N}-24^{\circ} \mathrm{N}, 122^{\circ} \mathrm{E}-124^{\circ} \mathrm{E}$, the distribution of the larger rainfall over northern Taiwan is completely different from mode2 and is clear evidence of distribution from mode-3. A similar situation is shown when typhoon centers are located inside sub-domain of $24^{\circ} \mathrm{N}-26^{\circ} \mathrm{N}, 116^{\circ} \mathrm{E}-120^{\circ} \mathrm{E}$ where the rainfall in coastal areas of southern Taiwan is not explained by mode- 1 and mode- 2 but mode- 3 .

\section{RAINFALL FORECASTING EVALUATIONS}

The first three EOF modes show the prevalent rainfall distribution when typhoons are near Taiwan. If the amplitudes are correctly predicted, these three modes will accrue about $66 \%$ of the total rainfall variances over the whole island. These three modes can even stand for the rainfall more effectively at some stations. For example, the correlation coefficients between the rainfall and the assembled rainfall by the first three modes (Fig. 7) at ALS and YMS are larger than 0.9. Areas of the coefficients larger than 0.8 cover the northern tip of Taiwan, central Taiwan, and southeastern Taiwan. It is worthwhile, particularly for those areas just mentioned, to explore the potential of using EOF modes in rainfall forecasting. For stations of smaller values in Fig. 7, they are either on offshore islands (PGY, PHO, and LYU) or in flat plains (TAN and KAS) both are relatively away from mountains. The results that conform to 


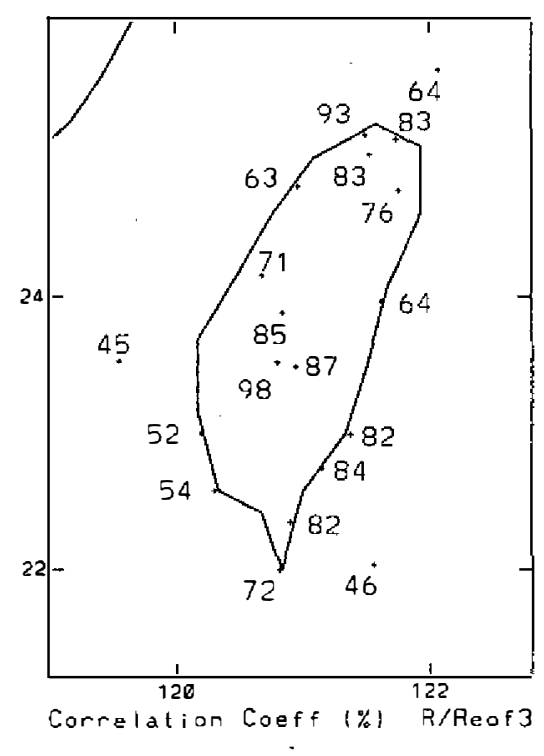

Fig. 7. The distribution of the correlation coefficients between station rainfall and the assembled rainfall from the first three empirical orthogonal function modes.

the first three modes are topography related rainfall distributions.

To explore the usage of EOF modes in typhoon rainfall forecasting, regression equations to forecast the amplitudes of EOF modes are developed. Rainfalls assembled from these modes are compared with forecasts by other methods. The methods compared include the Climatology Average Method (Wang et al. 1986), Deviation Persistence Method (Yeh et al. 1999), and a regression equations forecasting method. The Climatology Average Method is similar to that of using the mean rainfall in Fig. 4 to perform rainfall forecasting, except Fig. 4 was composted in $2^{\circ} \times 2^{\circ}$ sub-domains of coarser resolutions. In the following study, the mean rainfalls are composted in $0.5^{\circ} \times 0.5^{\circ}$ grids of finer resolutions. The rainfall of each case is averaged at the grid where the center is located. The rainfall of each case is also averaged at the neighboring eight grids from the center for obtaining smoother mean fields. Deviation Persistence Method, on the other hand, forecasts the rainfall not only based on the climatology mean but also considering that each typhoon maybe different from the others and assuming the rainfall deviating from the climatology mean will persist in time. Therefore, in any case, a more rain-laden typhoon will bring more rains later.

The regression equations rainfall forecasting method includes the forecast equation for each station. The equation predicts each of the 19 stations rainfall by using each of the 19 stations observed rainfall as dependent variables. The rainfall forecasting method based on EOF modes uses each of the observed amplitudes of the first three modes as dependent variables and predicts each of the amplitudes to construct rainfall at each of the 19 stations. To simplify the calculation, the independent variables are chosen from the current rainfall and the information obtained from the best track data. No other meteorological factors, although those may be significant to the typhoon rainfall forecasting, are included. In detail, the current typhoon center maximum wind speeds $(\mathrm{m} / \mathrm{s})$, moving speeds $(\mathrm{m} / \mathrm{s})$, moving directions (degree), center latitude and longitude locations (degree), Julian day function values (Neumann 1992), distances (degree) of typhoon centers from central Taiwan (defined at $24^{\circ} \mathrm{N}, 121^{\circ} \mathrm{E}$ ), and the 
rainfall (or the amplitudes of EOF modes in the second method) are used as the independent variables in the regression equations, in which the typhoon moving speeds and directions are calculated by the current and the past 6-hour typhoon center locations. The typhoon moving directions are prescribed as zero degrees when typhoons are moving southeastward to minimize the effect of discontinuity between $0^{\circ}$ and $360^{\circ}$.

As shown in Figs. 4 and 6, typhoon rainfall and the amplitudes of EOF modes depend on the typhoon center location but their relationship is not suitably represented by a simple linear function. Therefore, instead of formulating one regression equation for the whole set of data, a regression equation is built for each sub-set of data with centers located in the $2^{\circ} \times 2^{\circ}$ subdomains. To reduce the calculations and to limit the forecast of rainfall when a typhoon is located closer to Taiwan, the forecast verifications are performed on cases with typhoon center located inside a smaller domain of $20.5^{\circ} \mathrm{N}-26.5^{\circ} \mathrm{N}, 118.5^{\circ} \mathrm{E}-124.5^{\circ} \mathrm{E}$. For other areas of domain shown in Fig. 2, those typhoons are relatively far away from Taiwan when no or small rainfalls were observed over Taiwan. Therefore, those cases are not included in the rainfall forecast verifications.

Table 2 lists the skill scores of rainfall forecasts from CLImatology Average Method (CLI), DEviation Persistence Method (DEP), REgression equations forecast based on $\underline{\text { Station }}$ rainfall (RES), and REgression equations forecast based on EOF modes (REF). The homogenous comparisons are made by using independent data sets on model development and model forecast. The rainfalls of each 5-typhoon, grouped in sequence of the time the typhoon occurred, are predicted by methods built (such as the mean fields and regression equations) from the rest of typhoons. From 1961 to 1996 there were 4,387 cases allowing homogeneous forecast comparisons. The verification scores include the correlation coefficients between the observed rainfall and the forecasts (CC), the equitable threat scores (ETS) and the bias scores (BIAS), both at the threshold of $50 \mathrm{~mm}$. The numbers of cases of rainfall larger than $50 \mathrm{~mm}$ at each station are also listed. For easier elucidation, a functional format "SCORE(METHOD, STATION)" is introduced to represent the verification SCORE of forecasting results from a METHOD at a STATION, where the SCORE can be CC, ETS, or BIAS, the METHOD can be CLI, DEP, RES, or REF, and the STATION can either be any one of the 19 station-codes or be omitted. When the STATION is omitted, the scores are for all or for some of the stations depend on the descriptions.

Table 2 shows that the rainfall and the rainfall forecasting results both are very different among stations. The numbers of cases of larger than $50 \mathrm{~mm}$ rainfall are more than 600 cases at YMS, ALS and YUS while these are less than 200 cases at LYU and PHO. About the forecasting results from Climatology Average Method, CC(CLI) is from 0.37 (at KAS) to 0.56 (at YMS) with an averaged value of 0.46. Although some of CC(CLI) are close to or larger than 0.5 , the ETS(CLI) and BIAS(CLI) are all very small except at YMS, ZYT and ALS. An example of the scattering diagram of the forecasts at TPE is plotted in Fig. 8a. As discussed by Yeh et al. (1999), Climatology Average Method is capable of providing a rough trend of typhoon rainfall, but the method underestimates all of the heavier rains.

Deviation Persistence Method is superior to Climetology Average Method at all of the 19 station forecasts. The range of CC(DEP)/ETS(DEP) is from $0.41 / 0.12$ to $0.72 / 0.45$ with an averaged value of $0.55 / 0.23$. As the example shows in Fig. $8 \mathrm{~b}$, more of the forecasts are lo- 
Table 2. List of forecast verification skill scores. The stations are in sequence of the station number shown in TABLE I. Abbreviations of the forecasting method and more explanations are in text. Values shaded indicate the best scores among the first four forecasting methods at each station.

\begin{tabular}{|c|c|c|c|c|}
\hline \multirow{2}{*}{$\begin{array}{c}\text { Station. } \\
\text { Code }\end{array}$} & Correlation Coefficients & Equitable Threat Scores $(50 \mathrm{~mm})$ & Bias Scores $(50 \mathrm{~mm})$ & \multirow{2}{*}{ Cases } \\
\hline & 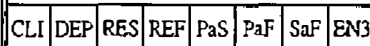 & 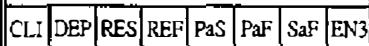 & \begin{tabular}{|l|l|l|l|l|l|l|} 
CLI DEP & RES & REF & PaS & PaF & SaF & EN
\end{tabular} & \\
\hline TPE & $64.59 \quad 360.65 .67 .68 .69$ & $0 \quad 1 \% .13,26.21 .25 .25 .26$ & $\begin{array}{llll}4 & 1.3 & 7 & 1.1 .\end{array}$ & 76 \\
\hline G & $16.49 .56 \% 4 \% .57 .59 .61 .61$ & .12 .28 .18 .17 & $\begin{array}{l:lllll}0 & 100 & .6 & .8 & .8 & .9\end{array}$ & 48 \\
\hline GY & $39.50 .49 .5 \% .52 .55 .53 .56$ & 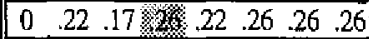 & $0.898 .7 \quad 1.2 .7$ & 286 \\
\hline AL & $46.50 \% .42 .54 \quad 54.52 .57$ & 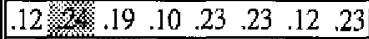 & $. 3 \longdiv { 1 \% } . 6 \quad 5$ & \\
\hline YMS & $56.73 \quad 7 \% .74 .77 .76 \quad .76 .77$ & $.23 .408 \% \times .42 .43 .45 .43 .46$ & $\begin{array}{llllllllll}.7 & 1.1 & 0 & 0 & 1.1 & 1.0 & 1.1 & 1.1 \\
\end{array}$ & $\overline{720}$ \\
\hline ILN & $\begin{array}{lllll}.47 .59 & 63 & .64 & .63 & .66 \\
\end{array}$ & \begin{tabular}{|llllllll}
0 & .19 & .18 & 20 & 20 & .21 & 20 & .22
\end{tabular} & \begin{tabular}{ll|lllll}
0 & 5 & .5 & .6 & .8 & .8 & .5
\end{tabular} & 82 \\
\hline$\overline{T A D}$ & 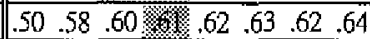 & $\begin{array}{lllllll}0 & 0.18 & .22 & 21 & .22 & 20 & .21\end{array}$ & $\begin{array}{lllllll}0 & 1.2 & .6 & 0 & .9 & 1.1\end{array}$ & 380 \\
\hline PHO & .49 W/ $\quad .49 .42 .56 \quad .57 \quad .52 \quad .58$ & 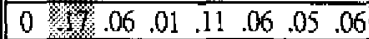 & $\begin{array}{lll}3 \% .6 \\
.3 & .2 & .6\end{array}$ & \\
\hline TAN & 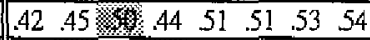 & $0.80 .14 .05 .13 .10 \quad .07 \quad .10$ & 00.5 & 258 \\
\hline KAS & $.37 .41 .38 \% 14.44 .47 .44 .48$ & $\begin{array}{lllllllll}0 & 1 & .07 & 02 & .12 & .09 & .02 & .10 \\
\end{array}$ & 026061 & 255 \\
\hline ZYT & 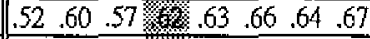 & 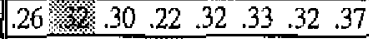 & 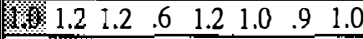 & 375 \\
\hline TAC & 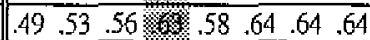 & 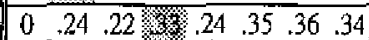 & $\begin{array}{lllllll}0 & 1 & 6 & 1.3 & .8 & 1.1\end{array}$ & 298 \\
\hline ALS & 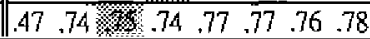 & $.24 \quad 4 \% 39.36 .44 \quad .43$ & 1.4 带带 1.21 .4 & 803 \\
\hline W & 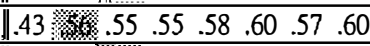 & 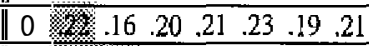 & \begin{tabular}{lllllll|}
0 & & .6 & 1.3 & .9 & 1.1 \\
\end{tabular} & 463 \\
\hline YUS & $.39 .64 \$ 63.59 .68 .66 .65 .68$ & $.04 .36 .32 .36 .36 \quad .35 \quad .37$ & .3 . & 622 \\
\hline SGU & 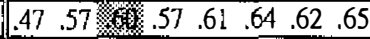 & 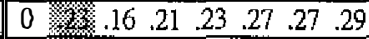 & $\begin{array}{lllllll}0 & 0 & 1.5 & 1.8 & .7 & 1.2 & 1.1 \\
\end{array}$ & 237 \\
\hline $\mathrm{HCN}$ & $.43 .49 .49 \quad \$ 98.53 .55 .53 .56$ & $\begin{array}{lllllll}.04 & .22 & .19 & .22 & .21 & .19 & .22 \\
\end{array}$ & $\begin{array}{llllll}.2 & .1 .0 & .8 & .6 & 1.0 & .9\end{array}$ & 444 \\
\hline $\mathrm{CKG}$ & 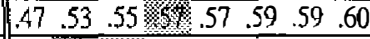 & 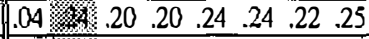 & \begin{tabular}{|llll}
.2 & 1.2 & .8 & 3
\end{tabular} & 458 \\
\hline$\overline{\mathrm{LYU}}$ & 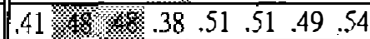 & $\begin{array}{llllllll}0 & 10 & .10 & .08 & .14 & .13 & .09 & .12\end{array}$ & 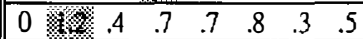 & 194 \\
\hline ximun & 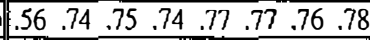 & 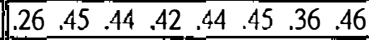 & $\begin{array}{lllllllll}1.4 & 1.2 & 1.2 & 1.4 & 1.2 & 1.2 & 1.1 & 1.2\end{array}$ & 803 \\
\hline Iт74 & .37 .41 .38 .38 .44 .47 .44 .48 & $\begin{array}{llllllll}0 & .12 & .06 & .01 & .11 & .06 & .05 & .06\end{array}$ & $\begin{array}{|lllllll|}0 & 1.0 & .3 & .1 & .6 & .4 & .2 \\
\end{array}$ & 127 \\
\hline & & & $\begin{array}{|lll|}2 & 1.1 & .7\end{array}$ & \\
\hline
\end{tabular}

cated near the diagonal of the scattering diagram than in Fig. 8a. CC(DEP,TPE) and ETS (DEP,TPE) are 0.59 and 0.2, respectively. At several other stations, Deviation Persistence Method provides the similar or better forecasting performance as at TPE. However, as mentioned by Yeh et al. (1999), Deviation Persistence Method usually underestimates/overestimates the heavier rains at the beginning/ending stage of the rainfall events. Therefore, CC (DEP) are not improved significantly from CC(CLI) although BIAS(DEP) are close to no bias.

About the forecasts from regression equations based on station rainfall (RES), CC(RES) are larger than CC(DEP) at 14 of 19 stations. But, the scores of predicting larger than $50 \mathrm{~mm}$ rainfall events are slightly worse than those by Deviation Persistence Method. Several BIAS (RES) are much smaller than 1.0 and the averaged value of ETS(RES) is 0.2 , which is smaller than that of ETS(DEP). As the example shows in Fig. 8c, the forecasts of RES are less scattered than DEP, but for heavier rainfall events, especially for rains greater than $100 \mathrm{~mm}$, more forecasts are underestimated. This agrees that BIAS(RES) are low biased and ETS(RES) are smaller than ETS(DEP), but CC(RES) are larger than CC(DEP).

The mean correlation coefficients and the mean equitable threat scores of forecasts from regression equations based on EOF modes (REF) are both very similar to those of RES. For 
(a) TPE 6h RAINFALL No=4387 CLI

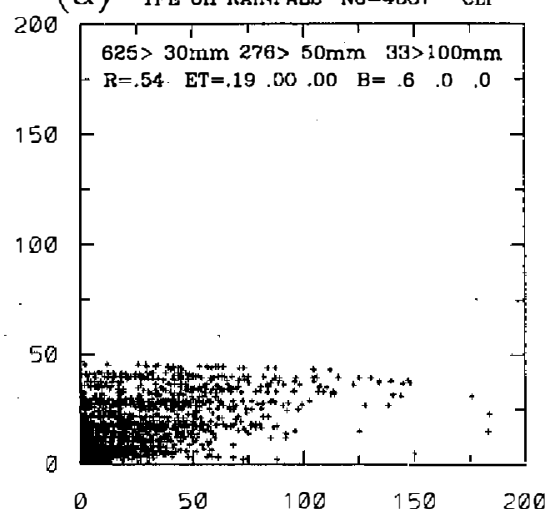

(C) TPE 6h RAINFALL No=4397 RES

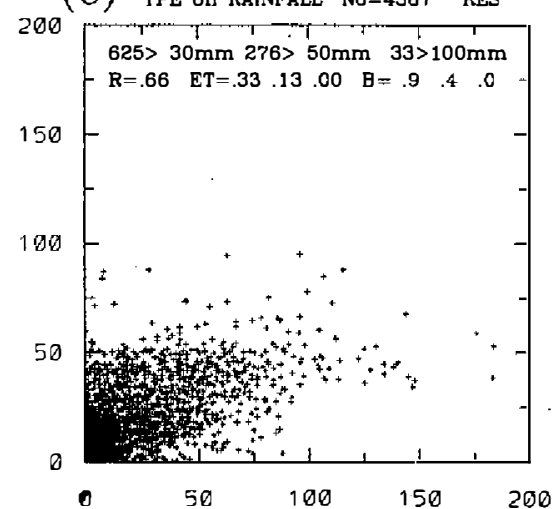

(e) TPE 6h RAINFALI. No $=4387$ SaF

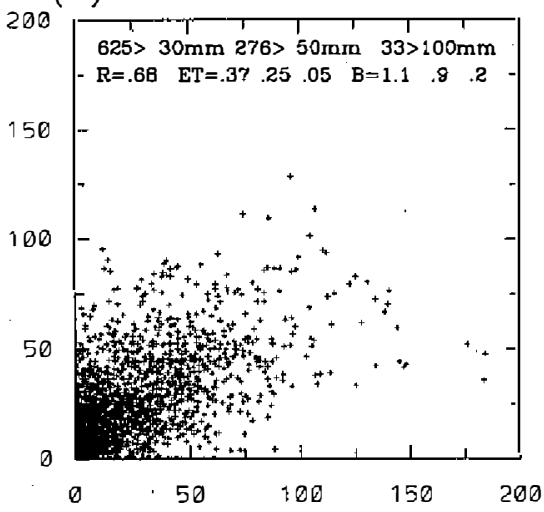

(b) TPE 6h RAINFALL No $=4387$ DEP

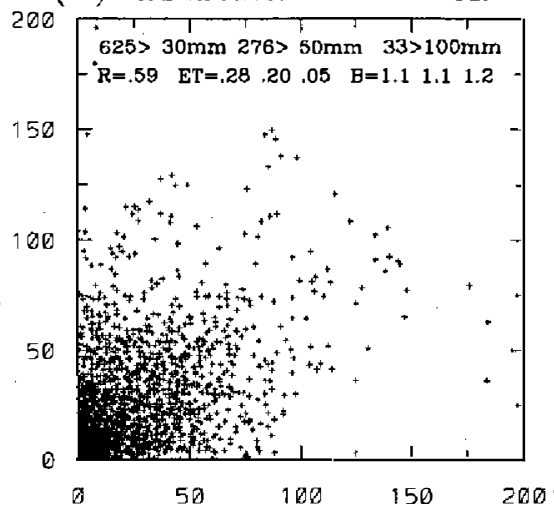

(d) TPE 6h RAINFALL No $=4387$ REF

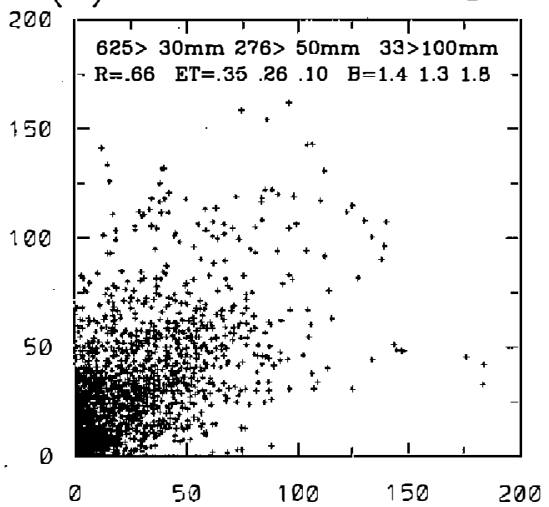

(f) TPE 6 h RAINFALL No=4387 EN3

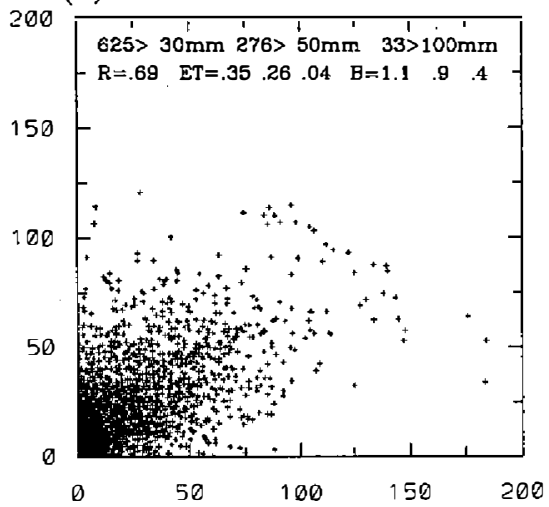

Fig. 8. Scattering diagrams show the distribution of the forecasting rainfall (vertical axes, mm) from (a) CLI, (b) DEP, (c) RES, (d) REF, (e) SaF, and (f) EN3 verse the observed rainfall (horizontal axes, $\mathrm{mm}$ ) at Taipei. Abbreviations of the forecasting methods are given in text. The scores of correlation coefficient (R), and equitable threat score (ET) and bias score (B) at thresholds 30,50 , and $100 \mathrm{~mm}$ are also printed. 
example, the averaged value of $\mathrm{CC}(\mathrm{REF}) / \mathrm{ETS}(\mathrm{REF})$ is $0.56 / 0.2$, resembling that of $\mathrm{CC}(\mathrm{RES}) /$ ETS(RES). However, two forecasting results are different at each station and REF provides slightly better unbiased forecasts than RES does. At 10 of the 19 stations, CC(REF) are the largest or equal to the largest correlation coefficients among the four forecasting methods. At seven stations, CC(REF) are greater than 0.6 and ETS(REF) are greater than 0.2. At some other stations, such as HAL, PHO, TAN, KAS, and LYU, their CC(REF) and ETS(REF) are relatively small. For those stations, we found that the first three modes are not enough to represent the station rainfall. Their correlation coefficients between station rainfall and the assembled rainfall from the first three EOF modes (Fig. 7) are small. Therefore, it is concluded that using the first three EOF modes to develop typhoon rainfall forecasting model is helpful to the operation, especially for those areas where the first three EOF modes well depict the station rainfall.

In addition to listing the forecast verification scores from the four basic methods, four ensemble forecasting results are also presented in Table 2 . The ensemble forecasting methods include $\mathrm{PaS}, \mathrm{PaF}, \mathrm{SaF}$, and EN3. Those methods are simply the averages of the forecasting results from two or three basic methods. $\mathrm{PaS}, \mathrm{PaF}$, and $\mathrm{SaF}$ discriminate methods of taking the mean of DEP and RE $\underline{S}$, DEP and REE, RE $\underline{S}$ and REE, respectively. EN3 denotes the ensemble forecasting method of averaging all three forecasting results from DEP, RES, and REF. Table 2 shows that each ensemble forecast is usually superior to the basic methods on which it is based. For example, the averaged value of the correlation coefficients of each ensemble forecast is larger than those of its corresponding basic methods. The averaged value of the equitable threat score of each ensemble forecast is also larger than or equal to those of its corresponding basic methods. At individual station, $\mathrm{CC}(\mathrm{PaF})$ are also greater than both of $\mathrm{CC}(\mathrm{DEP})$ and $\mathrm{CC}(\mathrm{REF})$ at all 19 stations. For $\mathrm{CC}(\mathrm{PaS})$ and $\mathrm{CC}(\mathrm{SaF})$, there are only 1 and 2 stations, respectively, where the correlation coefficient of the ensemble forecasts are smaller than those of their corresponding basic method forecasts. Figure 8e displays an example of the scattering diagram of the rainfall forecasts from $\mathrm{SaF}$. By averaging two forecasting results from RES and REF, some errors of underestimating the larger than $100 \mathrm{~mm}$ rainfall events (as in Fig. 8c) and overestimating the smaller than $50 \mathrm{~mm}$ rainfall events (as in Fig. 8d) are improved.

About the ensemble forecast of averaging all three forecasts of DEP, RES and REF, CC (EN3) are the largest correlation coefficients among all forecasts at all stations. ETS(EN3) are the largest or equal to the largest equitable threat scores among all forecasts at 10 of the 19 stations. The averaged value of BIAS(EN3) equals 0.8 . Therefore, EN3 may be concluded as the best forecasting method among those examined in Table 2. Figure $8 \mathrm{f}$ displays an example of the scattering diagram of the EN3 rainfall forecasts at TPE. The scattering distribution in Fig. $8 \mathrm{f}$ is similar to that of Fig. 8e and shows EN3 provides better forecasts than those of CLI, DEP, RES and REF. The correlation coefficients of EN3 at 19 stations are shown in Fig. 9. CC (EN3) are greater than 0.6 at most of the stations except on southern Taiwan (PHO, TAN, KAS, HCN, and LYU) and at HAL and PGY. Except HCN, those stations of CC(EN3) smaller than 0.6, the correlation coefficients between station rainfall and the assembled rainfall from the first three EOF modes are also smaller than 0.65 (Fig. 7). For those areas where higher order modes are required to delineate their rainfall and their rainf all are not well predicted by Deviation Persistence Method, the rainfall at those stations perhaps exist in a smaller scale, in 


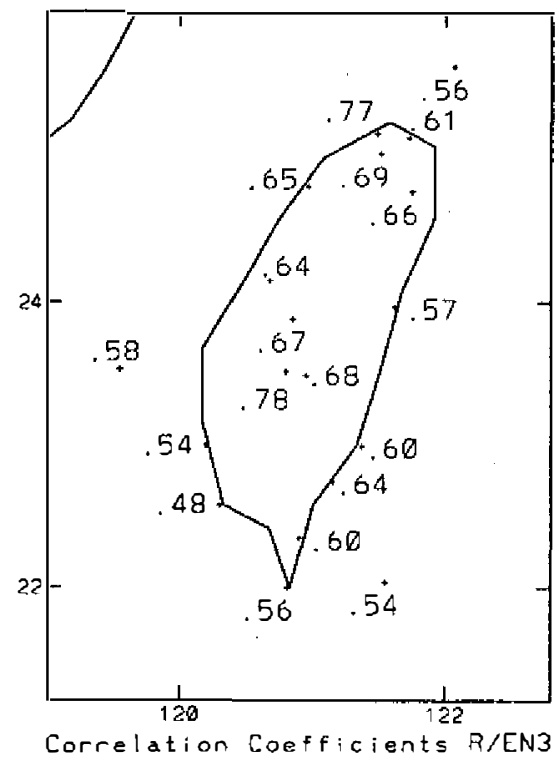

Fig. 9. The distribution of the correlation coefficients between the observed rainfall and the forecasting rainfall from EN3. The abbreviation of forecasting method EN3 is explained in text.

length and in time, features.

\section{SUMMARY}

Typhoon rainfall forecasting is a crucial issue of the weather service in Taiwan. Several simple statistical methods have been developed and been applied in the typhoon rainfall forecasting operation of Central Weather Bureau. However, more studies to understand the nature of typhoon rainfall and to develop more skillful objective forecasting guidance is still desired. This study has tried to show the 6-hour accumulated typhoon rainfall distribution based on empirical orthogonal function (EOF) analysis and to demonstrate an application of using the EOF modes on typhoon rainfall forecasting.

The data set used is the hourly rainfall observations at 20 surface stations of Central Weather Bureau when typhoons were inside the domain of $18^{\circ} \mathrm{N}-28^{\circ} \mathrm{N}, 116^{\circ} \mathrm{E}-126^{\circ} \mathrm{E}$ during 1961 to 1996. The best track data from Joint Typhoon Waming Center, Hawaii, United States were applied to define the center locations. A total of 14,747 cases of 6-h accumulated rainfall were analyzed directly without applying any interpolations to uniform grids, except the averaged rainfall of a pair of nearby stations, 46691 and 46693, were used in the EOF analysis. As a result, $19 \mathrm{EOF}$ modes were obtained. The percentage of the variances of each mode showed that the first three modes contain a relatively large percentage of variances and are well separated from the other modes. Therefore, only the first three rainfall EOF modes were further discussed.

The analysis results showed that the spatial pattern of the first EOF mode has a uniform sign at all 19 stations. The amplitude of the first EOF mode depends primarily on the location of typhoon center. Larger amplitudes occur when centers move close to Taiwan. The mode represents the in-phase increasing/decreasing of rainfall over the entire area of Taiwan when 
typhoons are moving close-to/away-from the island. Addition to the in-phase change of rainfall, the pattern of EOF mode one also depicts larger rainfall changes are at areas of higher elevation with steeper slop. This topography related distribution is an indication of the enhancement of rainfall due to topography effect.

The analysis results also showed that both the patterns of the second and the third EOF modes have out-of-phase distribution among stations. When the rainfall over an area is enhanced, the rainfall over the other area will be suppressed. The amplitudes of both modes also depend primarily on the typhoon center location. Larger rainfall will be enhanced/suppressed by these mode when typhoon centers are at locations of which the stations are in the upstream/downstream side of the lower level cyclonic winds flowing against the maintain. EOF mode 2 and EOF mode 3 are distinct indications of redistributing typhoon rainfall by mountains of Taiwan.

The first three modes contain about $66 \%$ of the total variances of the 19-station rainfall. How well the rainfalls can be represented by these three modes is different among stations. Since the first three modes are topography related, the rainfall at stations farther away from mountain are generally less well represented by the first three modes. For those stations, higher order modes are required to adequately describe their rainfall. In other words, the rainfalls at those stations contain smaller spatial scale features.

To demonstrate the application of EOF modes on typhoon rainfall forecasting, a regression equations rainfall forecasting method based on EOF mode amplitudes has been developed. Forecast verifications from several forecasting methods were also discussed. The forecasting methods compared include four basic methods: Climatology Average Method (Wang et al. 1986), Deviation Persistence Method (Yeh et al. 1999), the regression equation rainfall forecasting method based on the station rainfall (RES), and the regression equation forecasting method based on the first three rainfall EOF modes (REF), and the ensemble forecasts based on the last three basic methods. From the forecast verifications the following results were yielded:

1. Climatology Average Method is capable of providing a general trend of rainfall distribution but it underestimates, and is low biased for, all of the larger rains. Deviation Persistence Method usually provides better forecasts than Climatology Average Method does. The mean bias score of Deviation Persistence Method forecasting $50 \mathrm{~mm}$ rainfall events is about 1.1, that is close to unbiased. But, the forecasts from Deviation Persistence Method are more scattered in the scattering diagram. Larger error occurred because the method usually was not able to correctly forecast the starting time and the ending time of larger rainfall events.

2. The forecasting scores of the two kinds of regression equation forecasting methods are relatively similar. The 19-station mean correlation coefficients of these two methods are alike and are both slightly larger than that of Deviation Persistence Method. The 19-station mean equitable thread scores of these two methods are also very similar and are both slightly smaller than that of Deviation Persistence Method. None of the three methods outperformed the others.

3. REF method considered the spatial distribution of the rainfall events and eliminated the smaller spatial scale noises. The method can provide different information from the regression equation forecasting method based on single station rainfall. Although the averages of forecasting scores of these two kinds of regression equation forecasting methods are rela- 
tively similar, the scores at each station are different. For those stations where the rainfall can be well represented by the first three EOF modes, REF usually can provide more useful forecasts.

4. The ensemble forecasts, simple averaging technique applied, usually outperform the member forecasts they are based on. The 19-station mean correlation coefficient has been improved to 0.62 and the 19-station mean equitable threat score has been improved to 0.25 by the method of taking the averaged values from Deviation Persistence Method, RES and REF. For stations where the rainfall can be more suitably represented by the first three EOF modes, the forecast performances are generally better than those of the other stations.

In conclusion, terrain effects of redistributing typhoon rainfall over Taiwan were revealed through EOF analysis. For some stations, the first three EOF modes can effectively depict the total rainfall. We have demonstrated that for those stations the EOF analysis can be applied to develop a useful rainfall forecasting model and the forecasting method based on the EOF modes is different from a rainfall forecast method based solely on factors of one single station. Ensemble forecasts from these two kinds of methods were shown able to compensate for each weakness, resulting in better forecasts. In this study, the dependent variables of the regression equation forecast methods were limited in information contained in best track data. No other meteorological information was included. Yeh et al. (2001) has shown that the wind speed and the surface pressure at Taipei, the typhoon strength represented by the maximum wind speed, the typhoon moving speed, and the typhoon moving direction are all significant parameters affecting Taipei rainf all during the invasion of typhoons. For example, they showed that both the wind speed at Taipei and the typhoon strength generally have a positive impact on the Taipei rainfall. Stronger wind speeds and typhoon strengths usually bring along more intense rainfall. It will be very interesting to see the effect of those parameters included in the regression equation forecasting methods in the future.

Acknowledgments This study was supported by the Central Weather Bureau and the National Science Council under Grant NSC89-2625-Z-052-017. We also thank the reviewers for their valuable comments.

\section{REFERENCES}

Barnett, T. P., 1977: The principal time and space scales of the Pacific trade wind fields. $J$. Atmos. Sci., 34, 221-236.

Bender, M., R. Tuleya, and Y. Kurihara, 1987: A numerical study of the effect of island terrain on tropical cyclones. Mon. Wea. Rev., 115, 130-155.

Brand, S., and J. Blelloch, 1974: Changes in the characteristics of typhoons crossing the island of Taiwan. Mon. Wea. Rev., 102, 708-713.

Chang C.-P., T.-C. Yeh, and J. M. Chen, 1993: Effects of terrain on the surface structure of typhoons over Taiwan. Mon. Wea. Rev., 121, 734-752.

Chang, S. W., 1982: The orographic effects induced by an island mountain range on propagating tropical cyclones. Mon. Wea. Rev., 110, 1225-1270.

Chen L., 1995: Tropical cyclone heavy rainfall and damaging winds. Chapter 6, Global Per- 
spectives On Tropical Cyclones, WMO Report No. TCP-38, 260-289.

DeMaria M., and J. Kaplan, 1994: A Statistical Hurricane Intensity Prediction Scheme (SHIP) for the Atlantic Basin. Mon. Wea. Forecasting, 9, 209-220.

Elsberry, R. L., 1995: Tropical cyclone motion. Chapter 4, Global Perspectives On Tropical Cyclones, WMO Report No. TCP-38, 106-197.

Jarvinen, B. R., and C. J. Neumann, 1979: Statistical forecasts of ropical cyclone intensity, NOAA Tech. Memo. NWS NHC-10, 22pp.

Kuo Y.-H. and W. Wang, 1997: Rainfall prediction of typhoon Herb with a mesoscale model. Preprints, Workshop on Typhoon Research in the Taiwan Area, May 17-18, 1997, NCAR, Boulder, Colorado, 35-45.

Li J., N. E. Davidson, G. D. Hess, and G. Mills, 1997: A high-resolution prediction study of two typhoons at landfall. Mon. Wea. Rev., 125, 2856-2878.

Neumann, C. J., 1992: A revised climatology and persistence mode (WPCLPR) for the prediction of Western North Pacific tropical cyclone motion. SAIC/NORAL Contract Report N00014-90-C-6042 (PART I), 40pp.

Opitz, H. H., S. G. Summer, D. A. Wert, W. R. Snyder, R. J. Hane, R. H. Brady, P. H. Stokols, and G. M. Carter, 1995: The challenge of forecasting heavy rain and flooding throughout the eastern region of the National Weather Service. Part II: Forecast Technigues and applications. Wea. Forecasting, 10, 91-104.

Shieh, S.-L, 1986: A survey of meteorological disasters over Taiwan area (in Chinese). Atmos. Sci., 13, 89-108.

Wang, S.-T., 1980: Prediction of the behavior and strength of typhoons in Taiwan and its vicinity (in Chinese), Research Report No. 108, 100pp.

Wang, S.-T., C.-L. Yen, G. T. Chen, and S.-L. Shieh, 1986: The characteristics of typhoon precipitation and the prediction methods in Taiwan area (III) (in Chinese). Hazards Mitigation Program Technical Report 74-51, National Science Council, 152pp.

Wu, T.-Y., and K.-H. Chi, 1973: A study on the prediction of rainfall over Taiwan during typhoon invasion by analogue techniques (in Chinese). Meteorological Bulletin, 19(3), 10-19.

Wu, T.-Y., and S.-L. Shieh, 1990: On the applications of scientific results in meteorological research to typhoon forecast operations (III) (in Chinese). Research Report, NSC790414-P052-01B, Central Weather Bureau, 137pp.

Yeh, T.-C., and R. L. Elsberry, 1993: Interaction of typhoons with the Taiwan orography. Part I: Upstream rack deflections. Mon. Wea. Rev., 121, 3193-3212.

Yeh, T.-C., S.-C. Wu, and S.-L. Shieh, 1999: A study of typhoon rainfall statistics forecast over Taiwan area. Part I: methods and the forecast evaluations over Taipei (in Chinese). Atmos. Sci., 27, 395-412.

Yeh, T:-C., S.-L. Shieh, and S.-C. Wu, 2000: A study of typhoon rainfall statistics forecast over Taiwan area. Part II: Spatial distribution of the forecasts (in Chinese). Atmos. Sci., 28, 263-279.

Yeh, T.-C., T.-H. Fan, and Y.-H. Lee, 2001: Typhoon rainfall regression predictions over Taiwan area (I) The linear regression model for predicting typhoon rainfalls at Taipei (in Chinese). Atmos. Sci., 29, 77-96. 